\title{
Generalizations of graded second submodules
}

\author{
Peyman Ghiasvand \\ Department of Mathematics, \\ Payame Noor University, \\ P.O.BOX 19395-3697 Tehran, Iran. \\ email: p_ghiasvand@pnu.ac.ir
}

\author{
Farkhonde Farzalipour \\ Department of Mathematics, \\ Payame Noor University, \\ P.O.BOX 19395-3697 Tehran, Iran. \\ email: f_farzalipour@pnu.ac.ir
}

\begin{abstract}
Let $\mathrm{G}$ be a group with identity e. Let $\mathrm{R}$ be a graded ring, $\mathrm{I}$ a graded ideal of $R$ and $M$ be a G-graded R-module. Let $\psi: S^{g r}(M) \rightarrow$ $S^{{ }^{g}}(M) \cup\{\emptyset\}$ be a function, where $S^{{ }^{g r}}(M)$ denote the set of all graded submodules of $M$. In this article, we introduce and study the concepts of graded $\psi$-second submodules and graded I-second submodules of a graded R-module which are generalizations of graded second submodules of $M$ and investigate some properties of this class of graded modules.
\end{abstract}

\section{Introduction}

The study of graded rings arises naturally out of the study of affine schemes and allows them to formalize and unify arguments by induction [13]. However, this is not just an algebraic trick. The concept of grading in algebra, in particular graded modules is essential in the study of homological aspect of rings. Much of the modern development of the commutative algebra emphasizes graded rings. Graded rings play a central role in algebraic geometry and commutative algebra. Gradings appear in many circumstances, both in elementary and advanced level. In recent years, rings with a group-graded

2010 Mathematics Subject Classification: 13A02, 16W50

Key words and phrases: graded second submodule, graded $\psi$-second submodule, graded I-second submodule 
structure have become increasingly important and consequently, the graded analogues of different concepts are widely studied (see $[1,4,10,11,12,14]$ ). Throughout this work, all graded rings are assumed to be commutative graded rings with identity, and all graded modules are unitary graded R-modules. We will denote the set of graded ideals of $R$ by $S^{g r}(R)$ and the set of all graded submodules of $M$ by $S^{g r}(M)$. Let $G$ be a group with identity $e$ and $R$ be a ring. Then $R$ is said to be a $G$-graded if $R=\bigoplus_{g \in G} R_{g}$ such that $R_{g} R_{h} \subseteq R_{\text {gh }}$ for all $g, h \in G$, where $R_{g}$ is an additive subgroup of $R$ for all $g \in G$. The elements of $R_{g}$ are homogeneous of degree $g$. Consider $\operatorname{supp}(R, G)=\left\{g \in G \mid R_{g} \neq 0\right\}$. For simplicity, we will denote the graded ring $(R, G)$ by $R$. If $r \in R$, then $r$ can be written as $\sum_{g \in G} r_{g}$, where $r_{g}$ is the component $r$ in $R_{g}$. Moreover, $R_{e}$ is a subring of $R$ and if $R$ contains a unitary 1 , then $1 \in R_{e}$. Furthermore, $h(R)=\bigcup_{g \in G} R_{g}$.

Let $I$ be a left ideal of a graded ring $R$. Then $I$ is said to be a graded ideal of $R$, if $I=\bigoplus_{g \in G}\left(I \cap R_{g}\right)$, i. e., for $x \in I, x=\sum_{g \in G} x_{g}$, where $x_{g} \in I$ for all $\mathrm{g} \in \mathrm{G}$. A proper graded ideal I of a graded ring $R$ is said to be graded prime if whenever $r_{g} s_{h} \in I$ for some $r_{g}, s_{h} \in h(R)$, then $r_{g} \in I$ or $s_{h} \in I$. Graded primary (prime) ideals over commutative graded rings have been studied by [14].

Assume that $M$ is an R-module. Then $M$ is said to be $\mathrm{G}$-graded if $M=$ $\bigoplus_{g \in G} M_{g}$ with $R_{g} M_{h} \subseteq M_{g h}$ for all $g, h \in G$, where $M_{g}$ is an additive subgroup of $M$ for all $g \in G$. The elements of $M_{g}$ are called homogeneous of degree $\mathrm{g}$. Also, we consider $\operatorname{supp}(\mathrm{M}, \mathrm{G})=\left\{\mathrm{g} \in \mathrm{G} \mid \mathrm{M}_{\mathrm{g}} \neq 0\right\}$. It is clear that $M_{g}$ is an $R_{e}$-submodule of $M$ for all $g \in G$. Moreover $h(M)=\bigcup_{g \in G} M_{g}$. Let $\mathrm{N}$ be an R-submodule of a graded R-module $\mathrm{M}$. Then $\mathrm{N}$ is said to be a graded R-submodule if $N=\bigoplus_{g \in G}\left(N \cap M_{g}\right)$, i. e., for $m \in N, m=\sum_{g \in G} m_{g}$, where $\mathrm{m}_{\mathrm{g}} \in \mathrm{N}$ for all $\mathrm{g} \in \mathrm{G}$. Moreover, $\mathrm{M} / \mathrm{N}$ becomes a $\mathrm{G}$-graded module with $g$-component $(M / N)_{g}=\left(M_{g}+N\right) / N$ for $g \in G$.

A proper graded submodule $\mathrm{N}$ of a graded $\mathrm{R}$-module $\mathrm{M}$ is said to be graded prime, if $r_{g} m_{h} \in N$ where $r_{g} \in h(R)$ and $m_{h} \in h(M)$, then $m_{h} \in N$ or $r_{g} \in(N: M)$. A graded R-module $M$ is called graded prime, if the zero graded submodule is graded prime in $M$. For more information about graded prime submodules over commutative graded rings see [3, 7, 9]. A graded R-module $M$ is called graded finitely generated if $M=R m_{g_{1}}+R m_{g_{2}}+\cdots+R m_{g_{n}}$ for some $m_{g_{1}}, \cdots, m_{g_{n}} \in h(M)$. Farshadifar and Ansari-Toroghy in [5, 6] introduced the concepts of I-second submodules of $M$ and $\psi$-second submodules of $M$ which are two generalizations of second submodules of $M$. In the first section of this paper, we introduce and study the notion of graded $\psi$-second submodules of a graded R-module $M$ and we investigate some properties of such graded 
submodules. For example, in Theorem 7 , we characterize graded $\psi$-second submodules of a graded R-module $M$. In the second section, we introduce the notion of graded I-second submodules of a graded R-module $M$ and obtain some related results. For example, we prove when a graded submodule of a graded R-module is a graded I-second submodule.

\section{Graded $\psi$-second submodules}

In this section, we define and study graded $\psi$-second submodules of a graded module over a commutative graded ring.

The following Lemma is known, but we write it here for the sake of references.

Lemma 1 Let $\mathrm{M}$ be a graded module over a graded ring $\mathrm{R}$. Then the following hold:

(i) If $\mathrm{I}$ and $\mathrm{J}$ are graded ideals of $\mathrm{R}$, then $\mathrm{I}+\mathrm{J}$ and $\mathrm{I} \cap \mathrm{J}$ are graded ideals of $\mathrm{R}$.

(ii) If $\mathrm{I}$ is a graded ideal of $\mathrm{R}, \mathrm{N}$ is a graded submodule of $\mathrm{M}, \mathrm{r} \in \mathrm{h}(\mathrm{R})$ and $x \in h(M)$, then $R x, I N, r N$ and $\left(0:_{M} I\right)$ are graded submodules of $M$.

(iii) If $\mathrm{N}$ and $\mathrm{K}$ are graded submodules of $\mathrm{M}$, then $\mathrm{N}+\mathrm{K}$ and $\mathrm{N} \cap \mathrm{K}$ are also graded submodules of $\mathrm{M}$ and $\left(\mathrm{N}:_{\mathrm{R}} \mathrm{M}\right)$ is a graded ideal of $\mathrm{R}$. Also, $\operatorname{Ann}_{R}(M)=\left(0::_{R} M\right)$ is a graded ideal of $R$.

(iv) Let $\left\{\mathrm{N}_{\lambda}\right\}_{\lambda \in \Lambda}$ be a collection of graded submodules of $\mathrm{M}$. Then $\Sigma_{\lambda} \mathrm{N}_{\lambda}$ and $\bigcap_{\lambda} N_{\lambda}$ are graded submodues of $\mathrm{M}$.

Definition 1 Let $\mathrm{M}$ be a graded $\mathrm{R}$-module and let $\mathrm{g} \in \mathrm{G}$.

(a) A non-zero submodule $\mathrm{N}_{g}$ of $\mathrm{R}_{e}$ - module $\mathrm{M}_{\mathrm{g}}$ is said to be $\mathrm{g}$-second submodule of $\mathrm{M}_{\mathrm{g}}$, if for each $\mathrm{r}_{e} \in \mathrm{R}_{e}$, either $\mathrm{r}_{e} \mathrm{~N}_{\mathrm{g}}=0$ or $\mathrm{r}_{e} \mathrm{~N}_{\mathrm{g}}=\mathrm{N}_{\mathrm{g}}$.

(b) A non-zero graded submodule $\mathrm{N}$ of $\mathrm{M}$ is said to be a graded second submodule of $\mathrm{M}$ if for each $\mathrm{r}_{\mathrm{g}} \in \mathrm{h}(\mathrm{R})$, either $\mathrm{r}_{\mathrm{g}} \mathrm{N}=0$ or $\mathrm{r}_{g} \mathrm{~N}=\mathrm{N}$.

Definition 2 Let $\mathrm{M}$ be a graded $\mathrm{R}$-module and let $\mathrm{g} \in \mathrm{G}$. Let $\psi: \mathrm{S}\left(\mathrm{M}_{\mathrm{g}}\right) \rightarrow$ $S\left(M_{g}\right) \cup\{\emptyset\}$ be a function, where $S\left(M_{g}\right)$ is the set of all submodules of $M_{g}$. We say that a non-zero submodule $\mathrm{N}_{\mathrm{g}}$ of $\mathrm{R}_{e}$-module $\mathrm{M}_{\mathrm{g}}$ is a $\mathrm{g}-\psi$-second submodule, if $\mathrm{r}_{\mathrm{e}} \in \mathrm{R}_{e}, \mathrm{~K}$ a submodule of $\mathrm{M}_{\mathrm{g}}, \mathrm{r}_{\mathrm{e}} \mathrm{N}_{\mathrm{g}} \subseteq \mathrm{K}$, and $\mathrm{r}_{e} \psi\left(\mathrm{N}_{\mathrm{g}}\right) \nsubseteq \mathrm{K}$, then $\mathrm{N}_{\mathrm{g}} \subseteq \mathrm{K}$ or $\mathrm{r}_{\mathrm{e}} \mathrm{N}_{\mathrm{g}}=0$. 
Definition 3 Let $M$ be a graded R-module, $S^{{ }^{r}}(M)$ be the set of all graded submodules of $\mathrm{M}$, and let $\psi: \mathrm{S}^{{ }^{\mathrm{r}}}(\mathrm{M}) \rightarrow \mathrm{S}^{\mathrm{gr}^{\mathrm{r}}}(\mathrm{M}) \cup\{\emptyset\}$ be a function. We say that a non-zero graded submodule $\mathrm{N}$ of $\mathrm{M}$ is a graded $\psi$-second submodule of $\mathrm{M}$ if $\mathrm{r}_{\mathrm{g}} \in \mathrm{h}(\mathrm{R}), \mathrm{K}$ a graded submodule of $\mathrm{M}, \mathrm{r}_{\mathrm{g}} \mathrm{N} \subseteq \mathrm{K}$, and $\mathrm{r}_{\mathrm{g}} \psi(\mathrm{N}) \nsubseteq \mathrm{K}$, then $\mathrm{N} \subseteq \mathrm{K}$ or $\mathrm{r}_{\mathrm{g}} \mathrm{N}=0$

We use the following functions $\psi: S^{g r}(M) \rightarrow S^{g r}(M) \cup\{\emptyset\}$.

$$
\begin{aligned}
\psi_{M}(N) & =M, \forall N \in S^{g r}(M), \\
\psi_{i}(N) & =\left(N:_{M} \operatorname{Ann}_{R}^{i}(N)\right), \forall N \in S^{g r}(M), \forall i \in \mathbb{N}, \\
\psi_{\sigma}(N) & =\sum_{i=1}^{\infty} \psi_{i}(N), \forall N \in S^{g r}(M) .
\end{aligned}
$$

Then it is clear that for any graded submodule and every positive integer $\mathrm{n}$, we have the following implications:

$$
\begin{aligned}
\text { graded second } & \Rightarrow \text { graded } \psi_{n-1}-\text { second } \Rightarrow \text { graded } \psi_{n}-\text { second } \\
& \Rightarrow \text { graded } \psi_{\sigma}-\text { second }
\end{aligned}
$$

For functions $\psi, \theta: S^{g r}(M) \rightarrow S^{g r}(M) \cup\{\emptyset\}$, we write $\psi \leq \theta$ if $\psi(N) \subseteq \theta(N)$ for each $N \in S^{{ }^{g r}}(M)$. So whenever $\psi \leq \theta$, any graded $\psi$-second submodule is graded $\theta$-second.

Theorem 1 Let $\mathrm{M}$ be a graded $\mathrm{R}$-module and $\mathrm{N}$ be a graded submodule of $\mathrm{R}$. Then the following statements are equivalent:

(i) $\mathrm{N}$ is a graded second submodule of $\mathrm{M}$.

(ii) $\mathrm{N} \neq 0$ and $\mathrm{r}_{\mathrm{g}} \mathrm{N} \subseteq \mathrm{K}$, where $\mathrm{r}_{\mathrm{g}} \in \mathrm{h}(\mathrm{R})$ and $\mathrm{K}$ is a graded submodule of $\mathrm{M}$, implies either $\mathrm{r}_{\mathrm{g}} \mathrm{N}=0$ or $\mathrm{N} \subseteq \mathrm{K}$.

Proof. (i) $\Rightarrow$ (ii) is obvious.

(ii) $\Rightarrow$ (i) Let $r_{g} \in h(R)$ and $r_{g} N \neq 0$. Since $r_{g} N \subseteq r_{g} N$, so $N \subseteq r_{g} N$ by assumption. Therefore $r_{g} N=N$, as needed.

Theorem 2 Let $\mathrm{M}$ be a graded $\mathrm{R}$-module, $\mathrm{N}$ a graded submodule of $\mathrm{M}$ and let $\mathrm{g} \in \mathrm{G}$. Let $\boldsymbol{\psi}: \mathrm{S}\left(\mathrm{M}_{\mathrm{g}}\right) \rightarrow \mathrm{S}\left(\mathrm{M}_{\mathrm{g}}\right) \cup\{\emptyset\}$ be a function and $\mathrm{N}_{\mathrm{g}}$ be a $\mathrm{g}-\psi$-second submodule of $\mathrm{R}_{e}$-module $\mathrm{M}_{\mathrm{g}}$ such that $\operatorname{Ann}_{\mathrm{R}_{e}}\left(\mathrm{~N}_{\mathrm{g}}\right) \psi\left(\mathrm{N}_{\mathrm{g}}\right) \nsubseteq \mathrm{N}_{\mathrm{g}}$. Then $\mathrm{N}_{\mathrm{g}}$ is a $\mathrm{g}$-second submodule of $\mathrm{M}_{\mathrm{g}}$. 
Proof. Let $r_{e} \in R_{e}$ and $K$ be a submodule of $M_{g}$ such that $r_{e} N_{g} \subseteq K$. If $r_{e} \psi\left(N_{g}\right) \nsubseteq K$, then we are done because $N_{g}$ is a $g$ - $\psi$-second submodule of $R_{e}$-module $M_{g}$. Thus suppose that $r_{e} \psi\left(N_{g}\right) \subseteq K$. If $r_{e} \psi\left(N_{g}\right) \nsubseteq N_{g}$, then $r_{e} \psi\left(N_{g}\right) \nsubseteq N_{g} \cap K$. Since $r_{e} N_{g} \subseteq N_{g} \cap K$, then $N_{g} \subseteq N_{g} \cap K \subseteq K$ or $r_{e} N_{g}=$ 0 , as required. So let $r_{e} \psi\left(N_{g}\right) \subseteq N_{g}$. If $A_{n n} n_{R_{e}}\left(N_{g}\right) \psi\left(N_{g}\right) \nsubseteq K$, then $\left(r_{e}+\right.$ $\left.A n n_{R_{e}}\left(N_{g}\right)\right) \psi\left(N_{g}\right) \nsubseteq K$. Thus $\left(r_{e}+A n n_{R_{e}}\left(N_{g}\right)\right) N_{g} \subseteq K$ implies that $N_{g} \subseteq K$ or $r_{e} N_{g}=\left(r_{e}+A n n_{R_{e}}\left(N_{g}\right)\right) N_{g}=0$, as needed. Hence let $A n n_{R_{e}}\left(N_{g}\right) \psi\left(N_{g}\right) \subseteq$ K. Since $A n n_{R_{e}}\left(N_{g}\right) \psi\left(N_{g}\right) \nsubseteq N_{g}$, there exists $s_{e} \in A n n_{R_{e}}\left(N_{g}\right)$ such that $\left(s_{e} \psi\left(N_{g}\right) \nsubseteq N_{g}\right.$. Thus $s_{e} \psi\left(N_{g}\right) \nsubseteq N_{g} \cap K$. Hence we have $\left(r_{e}+s_{e}\right) \psi\left(N_{g}\right) \nsubseteq$ $\mathrm{N}_{\mathrm{g}} \cap \mathrm{K}$. Therefore, $\left(\mathrm{r}_{e}+s_{e}\right) \mathrm{N}_{\mathrm{g}} \subseteq \mathrm{N}_{\mathrm{g}} \cap \mathrm{K}$ implies that $\mathrm{N}_{\mathrm{g}} \subseteq \mathrm{N}_{\mathrm{g}} \cap \mathrm{K} \subseteq \mathrm{K}$ or $\left(r_{e}+s_{e}\right) N_{g}=r_{e} N_{g}=0$, as needed.

Corollary 1 Let $\mathrm{M}$ be a graded $\mathrm{R}$-module, $\mathrm{N}$ a graded submodule of $\mathrm{M}$ and $\mathrm{g} \in \mathrm{G}$. Let $\psi: \mathrm{S}\left(\mathrm{M}_{\mathrm{g}}\right) \rightarrow \mathrm{S}\left(\mathrm{M}_{\mathrm{g}}\right) \cup\{\emptyset\}$ be a function and $\mathrm{N}_{\mathrm{g}}$ be a $\mathrm{g}-\psi$-second submodule of $\mathrm{R}_{e}$-module $\mathrm{M}_{\mathrm{g}}$ such that $\left(\mathrm{N}_{\mathrm{g}}:_{\mathrm{M}_{\mathrm{g}}} \operatorname{Ann}_{\mathrm{R}_{e}}^{2}\left(\mathrm{~N}_{\mathrm{g}}\right) \psi\left(\mathrm{N}_{\mathrm{g}}\right) \subseteq \psi\left(\mathrm{N}_{\mathrm{g}}\right)\right.$. Then $\mathrm{N}_{\mathrm{g}}$ is a $\mathrm{g}-\psi_{\sigma}$-second submodule of $\mathrm{M}_{\mathrm{g}}$.

Proof. If $N_{g}$ is a $g$-second submodule of $M_{g}$, then the result is clear. So assume that $N_{g}$ is not $g$-second submodule of $M_{g}$. Then by Theorem 2, we have $\operatorname{Ann}_{R_{e}}\left(N_{g}\right) \psi\left(N_{g}\right) \subseteq N_{g}$. Therefore, by assumption,

$$
\left(\mathrm{N}_{g}: \mathrm{M}_{\mathrm{g}} \operatorname{Ann}_{\mathrm{R}_{e}}^{2}\left(\mathrm{~N}_{\mathrm{g}}\right)\right) \subseteq \psi\left(\mathrm{N}_{\mathrm{g}}\right) \subseteq\left(\mathrm{N}_{\mathrm{g}}:_{\mathrm{M}_{\mathrm{g}}} \operatorname{Ann}_{\mathrm{R}_{e}}\left(\mathrm{~N}_{\mathrm{g}}\right)\right) .
$$

We conclude that $\psi\left(N_{g}\right)=\left(N_{g}: M_{g} A_{n n}^{2}\left(N_{R_{e}}\right)\right)=\left(N_{g}:_{M_{g}} A n n_{R_{e}}\left(N_{g}\right)\right)$, because $\left(N_{g}:_{M_{g}} A n n_{R_{e}}\left(N_{g}\right)\right) \subseteq\left(N_{g}:_{M_{g}} A_{n n} R_{R_{e}}\left(N_{g}\right)\right)$. So we get

$$
\begin{gathered}
\left(N_{g}: M_{g} \operatorname{Ann}_{R_{e}}^{3}\left(N_{g}\right)\right)=\left(\left(\left(N_{g}:_{M_{g}} \operatorname{Ann}_{R_{e}}^{2}\left(N_{g}\right)\right):_{M_{g}} \operatorname{Ann}_{R_{e}}\left(\psi\left(N_{g}\right)\right)\right)=\right. \\
\left(\left(N_{g}: M_{g} A n n_{R_{e}}\left(N_{g}\right)\right):_{M_{g}} A n n_{R_{e}}\left(N_{g}\right)\right)=\left(N_{g}:_{M_{g}} A_{n n} n_{R_{e}}^{2}\left(N_{g}\right)\right)=\psi\left(N_{g}\right) .
\end{gathered}
$$

By continuing, we get that $\psi\left(N_{g}\right)=\left(N_{g}: M_{g} A n n_{R_{e}}^{i}\left(N_{g}\right)\right)$ for all $i \geq 1$. Hence $\psi\left(N_{g}\right)=\psi_{\sigma}\left(N_{g}\right)$, as needed.

Theorem 3 Let $M$ be a graded $R$-module and $\psi: S^{{ }^{g r}}(M) \rightarrow S^{g r}(M) \cup\{\emptyset\}$ be a function. Let $\mathrm{N}$ be a graded submodule of $\mathrm{M}$ such that for all graded ideals $\mathrm{I}$ and $\mathrm{J}$ of $\mathrm{R},(\mathrm{N}: \mathrm{M} \mathrm{I}) \subseteq(\mathrm{N}: \mathrm{M} J)$ implies that $\mathrm{J} \subseteq \mathrm{I}$. If $\mathrm{N}$ is not a graded second submodule of $\mathrm{M}$, then $\mathrm{N}$ is not a graded $\psi_{1}$-second submodule of $\mathrm{M}$.

Proof. Since $N$ is not a graded second submodule of $M$, there exists $r_{g} \in h(R)$ and a graded submodule $K$ of $M$ such that $r_{g} N \neq 0$ and $N \nsubseteq K$, but $r_{g} N \subseteq K$ 
by Theorem 1. We have $\mathrm{N} \nsubseteq \mathrm{N} \cap \mathrm{K}$ and $\mathrm{r}_{\mathrm{g}} \mathrm{N} \subseteq \mathrm{N} \cap \mathrm{K}$. If $\mathrm{r}_{\mathrm{g}}\left(\mathrm{N}: \mathrm{M} \operatorname{Ann}_{\mathrm{R}}(\mathrm{N})\right) \nsubseteq$ $N \cap K$, then $N$ is not a graded $\psi_{1}$-second submodule of $M$. Hence let $r_{g}(N: M$ $\left.\operatorname{Ann}_{R}(N)\right) \subseteq N \cap K$. Thus $r_{g}\left(N: M \operatorname{Ann}_{R}(N)\right) \subseteq N \cap K \subseteq N$. Therefore, $\left(N:_{M} A n n_{R}(N)\right) \nsubseteq\left(N: M r_{g}\right)$ and so by assumption, $r_{g} \in A n n_{R}(N)$, which is a contradiction.

Corollary 2 Let $M$ be a graded $R$-module and $\psi: S^{g r}(M) \rightarrow S^{g r}(M) \cup\{\emptyset\}$ be a function. Let $\mathrm{N}$ be a graded submodule of $\mathrm{M}$ such that for all graded ideals $\mathrm{I}$ and $\mathrm{J}$ of $\mathrm{R},\left(\mathrm{N}:_{\mathrm{M}} \mathrm{I}\right) \subseteq(\mathrm{N}: \mathrm{M} J)$ implies that $\mathrm{J} \subseteq \mathrm{I}$. Then $\mathrm{N}$ is a graded second submodule of $\mathrm{M}$ if and only if $\mathrm{N}$ is a graded $\psi_{1}$-second submodule of $\mathrm{M}$.

A graded R-module $M$ is said to be a graded multiplication module if for every graded submodule $N$ of $M$, there exists a graded ideal $I$ of $R$ such that $N=$ IM. It is easy to see that $M$ is a graded multiplication module if and only if $N=(N: M) M$ for each graded submodule $N$ of $M[8]$.

A graded R-module $M$ is said to be a graded comultiplication module if for every graded submodule $\mathrm{N}$ of $\mathrm{M}$, there exists a graded ideal $\mathrm{I}$ of $\mathrm{R}$ such that $\mathrm{N}=\left(0:_{M} \mathrm{I}\right)[2]$.

Definition 4 Let $\mathrm{R}$ be a graded ring and $\varphi: \mathrm{S}^{{ }^{\mathrm{r}}}(\mathrm{R}) \rightarrow \mathrm{S}^{\mathrm{gr}}(\mathrm{R}) \cup\{\emptyset\}$ be a function. A proper graded ideal $\mathrm{P}$ of $\mathrm{R}$ is called graded $\varphi$-prime, if for $\mathrm{a}_{\mathrm{g}}, \mathrm{b}_{\mathrm{h}} \in$ $h(R), a_{g} b_{h} \in P-\varphi(P)$, then $a_{g} \in P$ or $b_{h} \in P$.

Definition 5 Let $M$ be a graded R-module and $\varphi: S^{g r}(M) \rightarrow S^{g r}(M) \cup\{\emptyset\}$ be a function. A proper graded submodule $\mathrm{N}$ of $\mathrm{M}$ is said to be graded $\varphi$-prime, if for each $r_{g} \in h(R)$ and $m_{g} \in h(M), r_{g} m_{h} \in N \backslash \varphi(N)$, then $m_{h} \in N$ or $r_{g} \in(N: R M)$.

Theorem 4 Let $M$ be a graded $R$-module, $\varphi: S^{g r}(R) \rightarrow S^{g r}(R) \cup\{\emptyset\}$, and $\theta: S^{g r}(M) \rightarrow S^{g r}(M) \cup\{\emptyset\}$ be functions such that $\theta(P)=\varphi((P: R M)) M$. The following statements hold:

(i) If $\mathrm{P}$ is a graded $\theta$-prime submodule of $\mathrm{M}$ such that $\left(\theta(\mathrm{P}):_{\mathrm{R}} \mathrm{M}\right) \subseteq \varphi((\mathrm{P}: \mathrm{R}$ $\mathrm{M})$ ), then $\left(\mathrm{P}:_{\mathrm{R}} \mathrm{M}\right)$ is a graded $\varphi$-prime ideal of $\mathrm{R}$.

(ii) If $\mathrm{M}$ is a graded multiplication $\mathrm{R}$-module and $\left(\mathrm{P}:_{\mathrm{R}} \mathrm{M}\right)$ is a graded $\varphi$ prime ideal of $\mathrm{R}$, then $\mathrm{P}$ is a graded $\theta$-prime submodule of $\mathrm{M}$.

Proof. (i) Let $a_{g} b_{h} \in\left(P:_{R} M\right) \backslash \varphi\left(\left(P:_{R} M\right)\right)$ for some $a_{g}, b_{h} \in h(R)$. If $a_{g} b_{h} M \subseteq \theta(P)$, then $a_{g} b_{h} \in \varphi\left(\left(P:_{R} M\right)\right)$, a contradiction. Thus $a_{g} b_{h} M \nsubseteq$ 
$\theta(P)$. Therefore, $a_{g} M \subseteq P$ or $b_{h} M \subseteq P$ because $P$ is a graded $\theta$-prime submodule of $M$. Thus $a_{g} \in(P: R M)$ or $b_{h} \in(P: R M)$, as needed.

(ii) Let $a_{g} m_{h} \in P \backslash \theta(P)=P \backslash \varphi\left(\left(P:_{R} M\right)\right) M$. Then $a_{g}\left(\left(R m_{h}: R R\right)\right) M \subseteq P$. If $a_{g}\left(\left(P:_{R} M\right)\right) \subseteq \varphi\left(\left(R m_{h}:_{R} M\right)\right)$, then $a_{g}\left(\left(R m_{h}:_{R} M\right)\right) M \subseteq \varphi\left(\left(P:_{R} M\right)\right) M$. As $M$ is a graded multiplication $R$-module, we have $a_{g} m_{h} \in R m_{h}=\left(R m_{h}: R\right.$ $M) M$. Therefore, $a_{g} m_{h} \in \varphi\left(\left(P:_{R} M\right)\right) M$ which is a contradiction. Thus $a_{g}\left(\left(R m_{h}: R M\right)\right) \nsubseteq \varphi\left(\left(P:_{R} M\right)\right)$ and so by assumption, $a_{g} \in\left(P:_{R} M\right)$ or $\left(R m_{h}: M M\right) \subseteq\left(P:_{R} M\right)$, as needed.

Theorem 5 Let $M$ be a graded $\mathrm{R}$-module, $\varphi: \mathrm{S}^{\mathrm{gr}}(\mathrm{R}) \rightarrow \mathrm{S}^{\mathrm{gr}}(\mathrm{R}) \cup\{\emptyset\}$, and $\psi: S^{g r}(M) \rightarrow S^{g r}(M) \cup\{\emptyset\}$ be functions. Then the following hold:

(i) If $S$ is a graded $\psi$-second submodule of $M$ such that $A n_{R}(\psi(S)) \subseteq$ $\varphi\left(A \cap n_{R}(S)\right)$, then $A n_{R}(S)$ is a graded $\varphi$-prime ideal of $R$.

(ii) If $\mathrm{M}$ is a graded comultiplication $\mathrm{R}$-module, $\mathrm{S}$ is a graded submodule of $M$ such that $\psi(S)=\left(0: M \varphi\left(\operatorname{Ann}_{R}(S)\right)\right)$, and $A n_{R}(S)$ is a graded $\varphi$-prime ideal of $\mathrm{R}$, then $\mathrm{S}$ is a graded $\psi$-second submodule of $\mathrm{M}$.

Proof. (i) Let $a_{g} b_{h} \in A n n_{R}(S) \backslash \varphi\left(A n n_{R}(S)\right)$ for some $a_{g}, b_{h} \in h(R)$. Then $a_{g} b_{h} \psi(S) \neq 0$ by assumption. If $a_{g} \psi(S) \subseteq\left(0: M b_{h}\right)$, then $a_{g} b_{h} \psi(S)=0$, a contradiction. Thus $a_{g} \psi(S) \nsubseteq\left(0: M b_{h}\right)$. Therefore, $S \subseteq\left(0:_{M} b_{h}\right)$ or $a_{g} S=0$ because $S$ is a graded $\psi$-second submodule of $M$. Hence $a_{g} \in \operatorname{Ann}_{R}(S)$ or $b_{h} \in A n n_{R}(S)$, as required.

(ii) Let $a_{g} \in h(R)$ and $K$ be a graded submodule of $M$ such that $a_{g} S \subseteq K$ and $a_{g} \psi(S) \nsubseteq K$. As $a_{g} S \subseteq K$, we have $S \subseteq\left(K: M a_{g}\right)$. It follows that

$$
S \subseteq\left(\left(0:_{M} \operatorname{Ann}_{R}(K)\right):_{M} a_{g}\right)=\left(0: M a_{g} A n n_{R}(K)\right) .
$$

This implies that $a_{g} A n n_{R}(K) \subseteq A n n_{R}\left(\left(0: M a_{g} A n n_{R}(K)\right)\right) \subseteq A n n_{R}(S)$. Hence $a_{g} A n n_{R}(K) \subseteq A n_{R}(S)$. If $a_{g} A n n_{R}(K) \subseteq \varphi\left(A n n_{R}(S)\right)$, then

$$
\psi(S)=\left(\left(0:_{M} \varphi\left(A n n_{R}(S)\right)=\left(\left(0::_{M} A n n_{R}(K)\right):_{M} a_{g}\right) .\right.\right.
$$

As $M$ is a graded comultiplication R-module, we have $a_{g} \psi(S) \subseteq K$, a contradiction. Thus $a_{g} A n n_{R}(K) \nsubseteq \varphi\left(A n n_{R}(S)\right)$ and so as $A n_{R}(S)$ is a graded $\varphi$-prime ideal of $R$, we conclude that $a_{g} S=0$ or

$$
S=\left(0: M \operatorname{Ann}_{R}(S)\right) \subseteq\left(0: M A n n_{R}(K)\right)=K
$$

as needed. 
Example 1 Let $\mathrm{G}=\mathbb{Z}_{2}$ and $\mathrm{R}=\mathbb{Z}$ be a $\mathrm{G}$-graded ring with $\mathrm{R}_{0}=\mathbb{Z}$ and $\mathrm{R}_{1}=\{0\}$. Let $\mathrm{M}=\mathbb{Z} \times \mathbb{Z}$. Then $\mathrm{M}$ is a $\mathrm{G}$-graded $\mathrm{R}$-module with $\mathrm{M}_{0}=\mathbb{Z} \times\{0\}$ and $M_{1}=\{0\} \times \mathbb{Z}$. Consider the graded submodule $S=(2 \mathbb{Z} \times\{0\}) \oplus(\{0\} \times$ $2 \mathbb{Z})$. Clearly, $\mathrm{M}$ is not a graded comultiplication R-module. Suppose that $\varphi$ : $S^{g r}(R) \rightarrow S^{g^{r}}(R) \cup\{\emptyset\}$ and $\psi: S^{g r}(M) \rightarrow S^{g r}(M) \cup\{\emptyset\}$ be functions such that $\varphi(\mathrm{I})=\mathrm{I}$ for each graded ideal $\mathrm{I}$ of $\mathrm{R}$ and $\psi(\mathrm{S})=\mathrm{M}$. Then $\operatorname{Ann}_{\mathrm{R}}(\mathrm{S})=0$ is a graded $\varphi$-prime ideal of $\mathrm{R}$ and $\psi(\mathrm{S})=\mathrm{M}=\left(0 \mathrm{:}_{\mathrm{M}} \varphi\left(\mathrm{Ann}_{\mathrm{R}}(\mathrm{S})\right)\right)$. But since $4 S \subseteq(8 \mathbb{Z} \times\{0\}) \oplus(\{0\} \times 8 \mathbb{Z}), S \nsubseteq(8 \mathbb{Z} \times\{0\}) \oplus(\{0\} \times 8 \mathbb{Z})$, and $4 S \neq 0$, we have $\mathrm{S}$ is not a graded $\psi$-second submodule of $\mathrm{M}$.

Let $R$ be a $G$-graded ring and $S \subseteq h(R)$ be a multiplicatively closed subset of $R$. Then the ring of fractions $S^{-1} R$ is a graded ring which is called the graded ring of fractions. Indeed, $S^{-1} R=\bigoplus_{g \in G}\left(S^{-1} R\right)_{g}$ where $\left(S^{-1} R\right)_{g}=\{r / s: r \in$ $R, s \in S$ and $g=(\text { degs })^{-1}($ degr $\left.)\right\}$. We write $h\left(S^{-1} R\right)=\bigcup_{g \in G}\left(S^{-1} R\right)_{g}[8]$.

Proposition 1 Let $M$ be a graded R-module, $\psi: S^{g r}(M) \rightarrow S^{{ }^{g r}}(M) \cup\{\emptyset\}$ be a function and $\mathrm{N}$ be a graded $\psi$-second submodule of $\mathrm{M}$. Then we have the following statements.

(i) If $\mathrm{K}$ is a graded submodule of $\mathrm{M}$ with $\mathrm{K} \subset \mathrm{N}$ and $\psi_{\mathrm{K}}: \mathrm{S}^{\mathrm{gr}}(\mathrm{M} / \mathrm{K}) \rightarrow$ $\mathrm{S}^{{ }^{\mathrm{r}}}(\mathrm{M} / \mathrm{K}) \cup\{\emptyset\}$ be a function such that $\psi_{\mathrm{K}}(\mathrm{N} / \mathrm{K})=\psi(\mathrm{N}) / \mathrm{K}$, then $\mathrm{N} / \mathrm{K}$ is a graded $\psi_{\mathrm{K}}$-second submodule of $\mathrm{M} / \mathrm{K}$.

(ii) Let $\mathrm{N}$ be a graded finitely generated submodule of $\mathrm{M}, \mathrm{S}$ be a multiplicatively closed subset of $R$ with $A n_{R}(N) \cap S=\emptyset$, and $S^{-1} \psi: S^{g^{r}}\left(S^{-1} M\right) \rightarrow$ $S^{g r}\left(S^{-1} M\right) \cup\{\emptyset\}$ be a function such that $\left(S^{-1} \psi\right)\left(S^{-1} N\right)=S^{-1} \psi(N)$. Then $\mathrm{S}^{-1} \mathrm{~N}$ is a graded $\mathrm{S}^{-1} \psi$-second submodule of $\mathrm{S}^{-1} \mathrm{M}$.

Proof. (i) Since $K \subset N$, then $N / K \neq 0$. Let $r_{g} \in h(R), L / K$ be a graded submodule of $M / K, r_{g}(N / K) \subseteq L / K$ and $r_{g} \psi(N / K) \nsubseteq L / K$. We get $r_{g} N \subseteq L$ and $r_{g} \psi(N) \nsubseteq$ L. Therefore, $r_{g} N=0$ or $N \subseteq L$ since $N$ is a graded $\psi$-second submodule of $M$. Hence $r_{g}(N / K)=0$ or $N / K \subseteq L / K$, as needed.

(ii) Since $N$ is graded finitely generated and $A n n_{R}(N) \cap S=\emptyset$, we get $S^{-1}(N) \neq$ 0 . Let $\frac{r}{s} \in h\left(S^{-1} R\right), S^{-1}(K)$ be a graded submodule of $S^{-1} M$ and $\frac{r}{s}\left(S^{-1} \psi\right)\left(S^{-1} N\right)$ $\nsubseteq S^{-1} \mathrm{~K}$. Thus we get $\mathrm{rN} \subseteq \mathrm{K}$ and $\mathrm{r} \psi(\mathrm{N}) \nsubseteq \mathrm{K}\left(\left(\mathrm{S}^{-1} \psi\right)\left(\mathrm{S}^{-1} \mathrm{~N}\right)=\mathrm{S}^{-1} \psi(\mathrm{N})\right)$. Hence $\mathrm{N} \subseteq \mathrm{K}$ or $\mathrm{rN}=0$ since $\mathrm{N}$ is a graded $\psi$-second submodule of $\mathrm{M}$. Therefore, $S^{-1} N \subseteq S^{-1} K$ or $\frac{r}{s} \psi\left(S^{-1} N\right)=0$, and so $S^{-1} N$ is a graded $S^{-1} \psi$-second submodule of $S^{-1} M$.

Let $R=\bigoplus_{g \in G} R_{g}$ and $S=\bigoplus_{g \in G} S_{g}$ be two graded ring. The function $f: R \rightarrow S$ is called a graded homomorphism, if 
(i) for any $a, b \in R, f(a+b)=f(a)+f(b)$,

(ii) for any $a, b \in R, f(a b)=f(a) f(b)$, and

(iii) $f\left(R_{g}\right) \subseteq S_{g}$ for any $g \in G$.

Proposition 2 Let $M$ and $M^{\prime}$ be graded R-modules and $f: M \rightarrow M^{\prime}$ be a graded monomorphism. Let $\psi: S^{g^{r}}(M) \rightarrow S^{g^{r}}(M) \cup\{\emptyset\}$ and $\psi^{\prime}: S^{g^{r}}\left(M^{\prime}\right) \rightarrow$ $S^{g r}\left(M^{\prime}\right) \cup\{\emptyset\}$ be functions such that $\psi\left(f^{-1}\left(N^{\prime}\right)\right)=f^{-1}\left(\psi^{\prime}\left(N^{\prime}\right)\right)$, for each graded submodule $\mathrm{N}^{\prime}$ of $\mathrm{M}^{\prime}$. If $\mathrm{N}^{\prime}$ is a graded $\psi$-second submodule of $\mathrm{M}^{\prime}$ such that $\mathrm{N}^{\prime} \subseteq \operatorname{Im}(\mathrm{f})$, then $\mathrm{f}^{-1}\left(\mathrm{~N}^{\prime}\right)$ is a graded $\psi$-second submodule of $\mathrm{M}$.

Proof. Since $N^{\prime} \neq 0$ and $N^{\prime} \subseteq \operatorname{Im}(f)$, we have $f^{-1}\left(N^{\prime}\right) \neq 0$. Let $a_{g} \in h(R)$ and $K$ be a graded submodule of $M$ such that $a_{g} f^{-1}\left(N^{\prime}\right) \subseteq K$ and $a_{g} \psi\left(f^{-1}\left(N^{\prime}\right)\right) \nsubseteq$ K. Then by assumptions, $a_{g} N^{\prime} \subseteq f(K)$ and $a_{g} \psi^{\prime}\left(N^{\prime}\right) \nsubseteq f(K)$. Thus $a_{g} N^{\prime}=0$ or $N^{\prime} \subseteq f(K)$. Therefore, $a_{g} f^{-1}\left(N^{\prime}\right)=0$ or $f^{-1}\left(N^{\prime}\right) \subseteq K$, as required.

A proper graded submodule $N$ of a graded $R$-module $M$ is said to be graded completely irreducible if $N=\bigcap_{i \in I} N_{i}$, where $\left\{N_{i}\right\}_{i \in I}$ is a family of graded submodules of $M$, implies that $N=N_{i}$ for some $i \in I$. It is easy to see that every graded submodule of $M$ is an intersection of graded completely irreducible submodules of $M$.

Remark 1 Let $\mathrm{N}, \mathrm{K}$ be graded submodules of a graded $\mathrm{R}$-module $\mathrm{M}$. To prove $\mathrm{N} \subseteq \mathrm{K}$, it is enough to show that if $\mathrm{L}$ is a graded completely irreducible submodule of $\mathrm{M}$ such that $\mathrm{K} \subseteq \mathrm{L}$, then $\mathrm{N} \subseteq \mathrm{L}$.

Proposition 3 Let $M$ be a graded R-module, $\psi: S^{g r}(M) \rightarrow S^{g r}(M) \cup\{\emptyset\}$ be a function and let $\mathrm{N}$ be a graded $\psi_{1}$-second submodule of $\mathrm{M}$. Then we have the following statements:

(i) If for $a_{g} \in h(R), a_{g} N \neq N$, then $\left(N: M A_{M}(N)\right) \subseteq\left(N: M a_{g}\right)$.

(ii) If $\mathrm{J}$ is a graded ideal of $\mathrm{R}$ such that $\mathrm{Ann}_{\mathrm{R}}(\mathrm{N}) \subseteq \mathrm{J}$ and $\mathrm{JN} \neq \mathrm{N}$, then $\left(\mathrm{N}: \mathrm{M}_{\mathrm{M}} \operatorname{Ann}_{\mathrm{R}}(\mathrm{N})\right)=(\mathrm{N}: \mathrm{M} J)$.

Proof. (i) By Remark 1, there exists a graded completely irreducible submodule $L$ of $M$ such that $a_{g} N \subseteq L$ and $N \nsubseteq$ L. If $a_{g} N=0$, then we get $\left(N:_{M}\right.$ $\left.\operatorname{Ann}_{R}(N)\right) \subseteq\left(N:_{M} a_{g}\right)$. Hence let $a_{g} N \neq 0$. Since $N$ is a graded $\psi_{1}$-second submodule of $M$, we have $a_{g}\left(N:_{M} \operatorname{Ann}_{R}(N)\right) \subseteq$ L. Now let $H$ be a graded completely irreducible submodule of $M$ such that $N \subseteq H$. Then $N \nsubseteq L \cap H$ and $a_{g} N \subseteq L \cap H$. Thus as $N$ is a graded $\psi_{1}$-second submodule of $M$, we 
have $a_{g}\left(N: M \operatorname{Ann}_{R}(N)\right) \subseteq L \cap H$. Hence $a_{g}\left(N: M A_{M}(N)\right) \subseteq H$. Therefore, $a_{g}\left(N: M \operatorname{Ann}_{R}(N)\right) \subseteq N$ by Remark 1. Hence $\left(N: M{ }_{M} \operatorname{Ann}_{R}(N)\right) \subseteq\left(N:_{M} a_{g}\right)$.

(ii) This follows from (i).

Theorem 6 Let $M$ be a graded R-module, $\psi: S^{g r}(M) \rightarrow S^{9 r}(M) \cup\{\emptyset\}$ be a function and let $\mathrm{g} \in \mathrm{G}$. If $\left(0:_{\mathrm{M}_{\mathrm{g}}} \mathrm{a}_{e}\right)$ is a $\mathrm{g}-\psi_{1}$-second submodule of $\mathrm{R}_{e}$-module $M_{g}$ such that $\left(0: M_{g} a_{e}\right) \subseteq a_{e}\left(0: M_{g} a_{e} A n n_{R}\left(0: M_{g} a_{e}\right)\right)$, then $\left(0: M_{g} a_{e}\right)$ is a $\mathrm{g}$-second submodule of $\mathrm{M}_{\mathrm{g}}$.

Proof. Let $N=\left(0: M_{g} a_{e}\right)$ be a $g-\psi_{1}$-second submodule of $M$. Then $\left(0::_{g}\right.$ $\left.a_{e}\right) \neq 0$. Let $b_{e} \in R_{e}$ and $K$ be a submodule of $M_{g}$ such that $b_{e}\left(0: M_{g}\right.$ $\left.a_{e}\right) \subseteq K$. If $b_{e}\left(N: M_{g} A n n_{R_{e}}(N)\right) \nsubseteq K$, then $b_{e}\left(0: M_{g} a_{e}\right)=0$ or $\left(0: M_{g}\right.$ $\left.a_{e}\right) \subseteq K$ since $\left(0: M_{g} a_{e}\right)$ is a $g-\psi_{1}$-second submodule of $M_{g}$. So let $b_{e}\left(N:_{M_{g}}\right.$ $\left.\operatorname{Ann}_{R_{e}}(N)\right) \subseteq K$. Now we have $\left(a_{e}+b_{e}\right)\left(0: M_{g} a_{e}\right) \subseteq K$. If $\left(a_{e}+b_{e}\right)\left(N: M_{g}\right.$ $\left.\operatorname{Ann}_{R_{e}}(N)\right) \nsubseteq K$, then as $\left(0: M_{g} a_{e}\right)$ is a $g-\psi_{1}$-second submodule of $M_{g}$, then $\left(a_{e}+b_{e}\right)\left(0: M_{g} a_{e}\right)=0$ or $\left(0: M_{g} a_{e}\right) \subseteq K$ and we are done. Hence assume that $\left(a_{e}+b_{e}\right)\left(N: M_{g} A n n_{R_{e}}(N)\right) \subseteq K$. Then $b_{e}\left(N:_{M_{g}} A_{n n n_{R_{e}}}(N)\right) \subseteq K$ gives that $\mathrm{a}_{e}\left(\mathrm{~N}: \mathrm{M}_{\mathrm{g}} A n n_{\mathrm{R}_{e}}(\mathrm{~N})\right) \subseteq \mathrm{K}$. Therefore by assumption, $\left(0:_{\mathrm{M}_{g}} \mathrm{a}_{e}\right) \subseteq \mathrm{K}$ and the result follows from Theorem 1.

Theorem 7 Let $M$ be a graded R-module, $\psi: S^{g r}(M) \rightarrow S^{g r}(M) \cup\{\emptyset\}$ be a functions, and $\mathrm{N}$ be a non-zero graded submodule of $\mathrm{M}$. Then the following are equivalent:

(i) $\mathrm{N}$ is a graded $\psi$-second submodule of $\mathrm{M}$;

(ii) For graded completely irreducible submodule $\mathrm{L}$ of $\mathrm{M}$ with $\mathrm{N} \nsubseteq \mathrm{L}$, we have $(\mathrm{L}: \mathrm{R} N)=\operatorname{Ann}_{\mathrm{R}}(\mathrm{N}) \cup(\mathrm{L}: \mathrm{R} \psi(\mathrm{N}))$;

(iii) For graded completely irreducible submodule $\mathrm{L}$ of $\mathrm{M}$ with $\mathrm{N} \nsubseteq \mathrm{L}$, we have $\left(L::_{R} N\right)=A n n_{R}(N)$ or $(L: R N)=(L: R \psi(N))$;

(iv) For any graded ideal $\mathrm{I}$ of $\mathrm{R}$ and any graded submodule $\mathrm{K}$ of $\mathrm{M}$, if $\mathrm{IN} \subseteq \mathrm{K}$ and $\mathrm{I} \psi(\mathrm{N}) \nsubseteq \mathrm{K}$, then $\mathrm{IN}=0$ or $\mathrm{N} \subseteq \mathrm{K}$.

(v) For each $\mathrm{a}_{\mathrm{g}} \in \mathrm{h}(\mathrm{R})$ with $\mathrm{a}_{\mathrm{g}} \psi(\mathrm{N}) \nsubseteq \mathrm{a}_{\mathrm{g}} \mathrm{N}$, we have $\mathrm{a}_{\mathrm{g}} \mathrm{N}=\mathrm{N}$ or $\mathrm{a}_{\mathrm{g}} \mathrm{N}=0$.

Proof. (i) $\Rightarrow$ (ii) Let for a graded completely irreducible submodule $L$ of $M$ with $N \nsubseteq$ L, we have $a_{g} \in(L: R N) \backslash(L: R \psi(N))$. Then $a_{g} \psi(N) \nsubseteq L$ L. Since $N$ is a graded $\psi$-second submodule of $M$, we have $a_{g} \in \operatorname{Ann}_{R}(N)$. As we may assume that $\psi(N) \subseteq N$, the other inclusion always holds. 
(ii) $\Rightarrow$ (iii) This follows from the fact that if a graded ideal is a union of two graded ideals, it is equal to one of them.

(iii) $\Rightarrow$ (iv) Let $I$ be a graded ideal of $R$ and $K$ be a graded submodule of $M$ such that $\mathrm{IN} \subseteq \mathrm{K}$ and $\mathrm{I} \psi(\mathrm{N}) \nsubseteq \mathrm{K}$. Suppose $\mathrm{I} \nsubseteq \mathrm{Ann}_{\mathrm{R}}(\mathrm{N})$ and $\mathrm{N} \nsubseteq \mathrm{K}$. We show that $I \psi(N) \subseteq K$. Let $a \in I$ and $L$ is a graded completely irreducible submodule of $M$ with $K \subseteq$ L. First, let $a \notin A n n_{R}(N)$. Then since $a N \subseteq L$, we have $\left(L::_{R} N\right) \neq \operatorname{Ann}_{R}(N)$. Hence by assumption $\left(L:_{R} N\right)=(L: R \psi(N))$. So $a \psi(N) \subseteq$ L. Now let $a \in I \cap A n n_{R}(N)$. Let $b \in I \backslash A n n_{R}(N)$. Then $a+b \in$ $\mathrm{I} \backslash A \operatorname{An}_{R}(\mathrm{~N})$. Hence by the first case, for each graded completely irreducible submodule $\mathrm{L}$ of $\mathrm{M}$ with $\mathrm{K} \subseteq \mathrm{L}$ we have $\mathrm{b} \psi(\mathrm{N}) \subseteq \mathrm{L}$ and $(\mathrm{b}+\mathrm{a}) \psi(\mathrm{N}) \subseteq \mathrm{L}$. This gives that $a \psi(N) \subseteq$ L. Thus in any case $a \psi(N) \subseteq$ L. Thus $I \psi(N) \subseteq$ L. Therefore, $a \psi(N) \subseteq K$ by Remark 1 .

(iv) $\Rightarrow$ (i) The proof is straightforward.

(i) $\Rightarrow\left(\right.$ v) Let $a_{g} \in h(R)$ such that $a_{g} \psi(N) \nsubseteq a_{g} N$. Then $a_{g} N \subseteq a_{g} N$ implies that $N \subseteq a_{g} N$ or $a_{g} N=0$ by part (i). Thus $N=a_{g} N$ or $a_{g} N=0$, as required. (v) $\Rightarrow$ (i) Let $a_{g} \in h(R)$ and $K$ be a graded submodule of $M$ such that $a_{g} N \subseteq K$ and $a_{g} \psi(N) \nsubseteq K$. If $a_{g} \psi(N) \subseteq a_{g} N$, then $a_{g} N \subseteq K$ implies that $a_{g} \psi(N) \subseteq K$, a contradiction. Thus by part (v), $a_{g} N=N$ or $a_{g} N=0$. Therefore, $\mathrm{N} \subseteq \mathrm{K}$ or $\mathrm{a}_{\mathrm{g}} \mathrm{N}=0$, as needed.

Example 2 Let $\mathrm{N}$ be a non-zero graded submodule of a graded $\mathrm{R}$-module $\mathrm{M}$ and let $\psi: S^{g r}(M) \rightarrow S^{g r}(M) \cup\{\emptyset\}$ be a function. If $\psi(N)=\mathrm{N}$, then $\mathrm{N}$ is a graded $\psi$-second submodule of $\mathrm{M}$ by Theorem $7(\mathrm{v}) \Rightarrow$ (i).

Let $R_{1}$ and $R_{2}$ be two $G$-graded rings. Then $R=R_{1} \times R_{2}$ becomes a $G$-graded ring with homogeneous elements $h(R)=\bigcup_{g \in G} R_{g}$, where $R_{g}=\left(R_{1}\right)_{g} \times\left(R_{2}\right)_{g}$ for all $g \in G$. Let $M_{1}$ be a graded $R_{1}$-module and $M_{2}$ be a graded $R_{2}$-module. Then $M=M_{1} \times M_{2}$ is a graded $R=R_{1} \times R_{2}$-module.

Theorem 8 Let $\mathrm{R}=\mathrm{R}_{1} \times \mathrm{R}_{2}$ be a graded ring and $\mathrm{M}=\mathrm{M}_{1} \times \mathrm{M}_{2}$ be a graded $\mathrm{R}$-module where $\mathrm{M}_{1}$ is a graded $\mathrm{R}_{1}$-module and $\mathrm{M}_{2}$ is a graded $\mathrm{R}_{2}$-module. Suppose that $\psi^{i}: S\left(M_{i}\right) \rightarrow S\left(M_{i}\right) \cup\{\emptyset\}$ be a function for $i=1,2$. Then $S_{1} \times 0$ is a graded $\psi^{1} \times \psi^{2}$-second submodule of $\mathrm{M}$, where $\mathrm{S}_{1}$ is a graded $\psi^{1}$-second submodule of $\mathrm{M}_{1}$ and $\psi^{2}(0)=0$.

Proof. Let $\left(r_{g}, r_{g}^{\prime}\right) \in h(R)$ and $K_{1} \times K_{2}$ be a graded submodule of $M$ such that $\left(\mathrm{r}_{\mathrm{g}}, \mathrm{r}_{\mathrm{g}}^{\prime}\right)\left(\mathrm{S}_{1} \times 0\right) \subseteq \mathrm{K}_{1} \times \mathrm{K}_{2}$ and

$$
\left(r_{g}, r_{g}^{\prime}\right)\left(\left(\psi^{1} \times \psi^{2}\right)\left(S_{1} \times 0\right)\right)=r_{g} \psi^{1}\left(S_{1}\right) \times r_{g}^{\prime} \psi^{2}(0)=r_{g} \psi^{1}\left(S_{1}\right) \times 0 \nsubseteq K_{1} \times K_{2}
$$


Then $r_{g} S_{1} \subseteq K_{1}$ and $r_{g} \psi^{1}\left(S_{1}\right) \nsubseteq K_{1}$. Hence $r_{g} S_{1}=0$ or $S_{1} \subseteq K_{1}$ since $S_{1}$ is a graded $\psi^{1}$-second submodule of $M_{1}$. Therefore, $\left(r_{g}, r_{g}^{\prime}\right)\left(S_{1} \times 0\right)=0 \times 0$ or $\mathrm{S}_{1} \times 0 \subseteq \mathrm{K}_{1} \times \mathrm{K}_{2}$, as needed.

\section{$3 \quad$ Graded I-second submodules}

Definition 6 Let $\mathrm{R}$ be a graded ring, $\mathrm{M}$ be a graded $\mathrm{R}$-module and $\mathrm{I}$ be a graded ideal of $\mathbf{R}$.

(a) A proper graded ideal $\mathrm{P}$ of $\mathrm{R}$ is called graded $\mathrm{I}$-prime, if $\mathrm{a}_{\mathrm{g}} \mathrm{b}_{\mathrm{h}} \in \mathrm{P} \backslash \mathrm{IP}$, then $\mathrm{a}_{\mathrm{g}} \in \mathrm{P}$ or $\mathrm{b}_{\mathrm{h}} \in \mathrm{P}$.

(b) A proper graded submodule $\mathrm{N}$ of $\mathrm{M}$ is called graded I-prime, if $\mathrm{r}_{\mathrm{g}} \mathrm{m}_{\mathrm{h}} \in$ $\mathrm{N} \backslash \mathrm{IN}$, then $\mathrm{m}_{\mathrm{h}} \in \mathrm{N}$ or $\mathrm{r}_{\mathrm{g}} \in(\mathrm{N}: \mathrm{R} M)$.

Theorem 9 Let I be a graded ideal of a graded ring R. For a non-zero graded submodule $\mathrm{S}$ of a graded $\mathrm{R}$-module $\mathrm{M}$ the following statements are equivalent:

(i) For each $\mathrm{r}_{\mathrm{g}} \in \mathrm{h}(\mathrm{R})$, a submodule $\mathrm{K}$ of $\mathrm{M}, \mathrm{r}_{\mathrm{g}} \in\left(\mathrm{K}: \mathrm{R}_{\mathrm{R}} \mathrm{S}\right) \backslash\left(\mathrm{K}: \mathrm{R}\left(\mathrm{S} \mathrm{:}_{\mathrm{M}} \mathrm{I}\right)\right)$ implies that $\mathrm{S} \subseteq \mathrm{K}$ or $\mathrm{r}_{\mathrm{g}} \in \mathrm{Ann}_{\mathrm{R}}(\mathrm{S})$;

(ii) For each $\mathrm{r}_{\mathrm{g}} \notin\left(\mathrm{r}_{\mathrm{g}} \mathrm{S}:_{\mathrm{R}}\left(\mathrm{S} \mathrm{:}_{\mathrm{M}} \mathrm{I}\right)\right)$, we have $\mathrm{r}_{\mathrm{g}} \mathrm{S}=\mathrm{S}$ or $\mathrm{r}_{\mathrm{g}} \mathrm{S}=0$;

(iii) $(K: R S)=\operatorname{Ann}_{R}\left(S \cup\left(K::_{R}(S: M I)\right)\right.$, for any submodule $K$ of $M$ with $\mathrm{S} \nsubseteq \mathrm{K}$;

(iv) $\left(\mathrm{K}::_{\mathrm{R}} \mathrm{S}\right)=\operatorname{Ann}_{\mathrm{R}}(\mathrm{S})$ or $(\mathrm{K}: \mathrm{R} S)=(\mathrm{K}: \mathrm{R}(\mathrm{S}: \mathrm{M} \mathrm{I}))$, for any submodule $\mathrm{K}$ of $\mathrm{M}$ with $\mathrm{S} \nsubseteq \mathrm{K}$.

Proof. (i) $\Rightarrow$ (ii) Let $r_{g} \notin\left(r_{g} S: R(S: M I)\right)$. Then as $r_{g} S \subseteq r_{g} S$, we have $S \subseteq r_{g} S$ or $r_{g} S=0$ by part (i). Thus $r_{g} S=S$ or $r_{g} S=0$.

(ii) $\Rightarrow$ (i) Let $r_{g} \in h(R)$ and $K$ be a graded submodule of $M$ such that $r_{g} \in$ $\left(K:_{R} S\right) \backslash\left(K:_{R}(S: M I)\right)$. Then if $r_{g} \in\left(r_{g} S: R(S: M I)\right)$, then $r_{g} \in(K: R(S: M I))$ which is a contradiction. Thus $r_{g} \notin\left(r_{g} S: R(S: M I)\right)$. Now by part (ii), $r_{g} S=S$ or $r_{g} S=0$. So $S \subseteq K$ or $r_{g} S=0$, as needed.

(i) $\Rightarrow$ (iii) Let $r_{g} \in(K: R S)$ and $S \nsubseteq K$. If $r_{g} \notin(K: R(S: M I))$, then $r_{g} \in A n n_{R}(S)$ by part (i). Hence, $(K: R S) \subseteq A n n_{R}(S)$. If $r_{g} \in(K: R(S: M I))$, then $(K: R S) \subseteq(K: R(S: M I))$. Therefore, $\left(K:_{R} S\right) \subseteq \operatorname{Ann}_{R}(S) \cup\left(K:_{R}(S: M I)\right)$. The other inclusion always holds.

(iii) $\Rightarrow$ (iv) and (iv) $\Rightarrow$ (i) are clear. 
Definition 7 Let I be a graded ideal of R. We say that a non-zero graded submodule $\mathrm{S}$ of a graded $\mathrm{R}$-module $\mathrm{M}$ is a graded $\mathrm{I}$-second submodule of $\mathrm{M}$, if satisfies the equivalent conditions of Theorem 9.

Let I be a graded ideal of R. Clearly, every graded second submodule is a graded I-second submodule. But the converse is not true in general.

Example 3 (a) If $\mathrm{I}=0$, then every graded module is a graded I-second submodule of itself but every graded module is not a graded second module. for example, let $\mathrm{G}=\mathbb{Z}_{2}, \mathrm{R}=\mathbb{Z}$ be a $\mathrm{G}$-graded ring with $\mathrm{R}_{0}=\mathbb{Z}$ and $\mathrm{R}_{1}=\{0\}$. Then it is clear that the graded $\mathrm{R}$-module $\mathrm{M}=\mathbb{Z}[\mathrm{i}]=\{\mathrm{a}+\mathrm{bi} \mid \mathrm{a}, \mathrm{b} \in \mathbb{Z}\}$ with $\mathrm{M}_{0}=\mathbb{Z}$ and $\mathrm{M}_{1}=\mathfrak{i} \mathbb{Z}$ is not a graded second module.

(b) Let $\mathrm{G}=\mathbb{Z}_{2}, \mathrm{R}=\mathbb{Z}$ and $\mathrm{M}=\mathbb{Z}_{12}[\mathrm{i}]=\left\{\overline{\mathrm{a}}+\overline{\mathrm{b}} \mathrm{i} \mid \overline{\mathrm{a}}, \overline{\mathrm{b}} \in \mathbb{Z}_{12}\right\}$. Then $\mathrm{R}$ is a $\mathrm{G}$-graded ring with $\mathrm{R}_{0}=\mathbb{Z}, \mathrm{R}_{1}=\{0\}$ and $\mathrm{M}$ is a graded $\mathrm{R}$-module with $M_{0}=\mathbb{Z}_{12}, M_{1}=i \mathbb{Z}_{12}$. Consider the grade ideal $\mathrm{I}=4 \mathbb{Z} \oplus\{0\}$ and the graded submodule $\mathrm{S}=\overline{3} \mathbb{Z} \oplus\{0\}$. Thus $\mathrm{S}$ is a graded $\mathrm{I}$-second submodule of $\mathrm{M}$, but it is not a graded second submodule of $\mathrm{M}$.

Let $I$ be a graded ideal of $R$ and $M$ be a graded $R$-module . If $I=R$, then every graded submodule is a graded I-second submodule. So in the rest of this paper we can assume that $\mathrm{I} \neq \mathrm{R}$.

Theorem 10 Let $\mathrm{M}$ be a graded $\mathrm{R}$-module and $\mathrm{I}, \mathrm{J}$ be graded ideals of $\mathrm{R}$ such that $\mathrm{I} \subseteq \mathrm{J}$. If $\mathrm{S}$ is a graded $\mathrm{I}$-second submodule of $\mathrm{M}$, then $\mathrm{S}$ is a graded $\mathrm{J}$-second submodule of $\mathrm{M}$.

Proof. The result follows from the fact that $I \subseteq J$ implies that $\left(r_{g} S:_{R} S\right) \backslash$ $\left(r_{g} S:_{R}(S: M J)\right) \subseteq\left(r_{g} S:_{R} S\right) \backslash\left(r_{g} S:_{R}\left(S:_{M} I\right)\right)$, for each $r_{g} \in R$.

Theorem 11 Let $\mathrm{M}$ be a graded $\mathrm{R}$-module and $\mathrm{g} \in \mathrm{G}$. If $\mathrm{I}$ is an ideal of $\mathrm{R}_{e}$ and $\mathrm{S}$ a $\mathrm{g}$-I-second submodule of $\mathrm{R}_{e}$-module $\mathrm{M}_{\mathrm{g}}$ which is not $\mathrm{g}$-second, then $\operatorname{Ann}_{R_{e}}(S)\left(S: M_{g} I\right) \subseteq S$.

Proof. Assume on the contrary that $\operatorname{Ann}_{R_{e}}(S)\left(S: M_{q}\right.$ I) $\nsubseteq S$. We show that $S$ is $g$-second. Let $r S \subseteq K$ for some $r \in R_{e}$ and a submodule $K$ of $M_{g}$. If $r \notin\left(\mathrm{K}: R_{e}\left(S: M_{g} I\right)\right)$, then $S$ is a $\mathrm{g}$-I-second submodule implies that $S \subseteq \mathrm{K}$ or $r \in A n n_{R_{e}}(S)$ as needed. So assume that $r \in\left(K: R_{e}\left(S: M_{g} I\right)\right)$. First, suppose that $r\left(S: M_{g} I\right) \nsubseteq S$. Then there exists a graded submodule $L$ of $M$ such that $S \subseteq L$ but $r_{g}\left(S: M_{g} I\right) \nsubseteq L$ L. Then $r \in\left(K \cap L: R_{e} S\right) \backslash\left(K \cap L::_{e}\left(S: M_{g} I\right)\right)$. So $S \subseteq \mathrm{K} \cap \mathrm{L}$ or $\mathrm{r}_{\mathrm{g}} \in \mathrm{Ann}_{\mathrm{R}_{e}}(\mathrm{~S})$ and hence $S \subseteq \mathrm{K}$ or $\mathrm{r} \in \mathrm{Ann}_{\mathrm{R}_{e}}(\mathrm{~S})$. So we can 
assume that $r\left(S:_{M_{g}} I\right) \subseteq S$. On the other hand, if $\operatorname{Ann}_{R_{e}}(S)\left(S:_{M_{g}} I\right) \nsubseteq K$, then there exists $t \in A_{n n n_{R_{e}}}(S)$ such that $t \notin\left(K: R_{e}\left(S: M_{g} I\right)\right)$. Then $t+r \in$ $\left(K: R_{e} S\right) \backslash\left(K::_{R_{e}}\left(S: M_{g} I\right)\right)$. Thus $S \subseteq K$ or $t+r \in A n n_{R_{e}}(S)$ and hence $S \subseteq K$ or $r \in A n n_{R_{e}}(S)$. So we can assume that $A n n_{R_{e}}(S)\left(S: M_{g} I\right) \subseteq K$. Since $A n n_{R_{e}}(S)\left(S: M_{g} I\right) \nsubseteq S$, there exists $t \in A_{n n} n_{R_{e}}(S)$, a submodule $L$ of $M$ such that $S \subseteq L$ and $t\left(S: M_{g} I\right) \nsubseteq L$. Now we have $r+t \in\left(K \cap L: R_{e} S\right) \backslash\left(K \cap L: R_{e}\right.$ $\left(S: M_{g} I\right)$ ). So $S$ is a $g$ - I-second submodule gives $S \subseteq K \cap L$ or $r+t \in A \operatorname{Ann}_{R_{e}}(S)$. Hence $S \subseteq K$ or $r \in A n_{R_{e}}(S)$, as requested.

Theorem 12 Let $\mathrm{I}$ be a graded ideal of $\mathrm{R}, \mathrm{M}$ a graded $\mathrm{R}$-module and $\mathrm{S}$ be a graded submodule of $\mathrm{M}$. Then we have the following.

(i) If $S$ is a graded I-second submodule of $M$ such that $A n_{R}((S: M I)) \subseteq$ $\mathrm{IAnn}_{\mathrm{R}}(\mathrm{S})$, then $\mathrm{Ann}_{\mathrm{R}}(\mathrm{S})$ is a graded I-prime ideal of $R$.

(ii) If $\mathrm{M}$ is a graded comultiplication $\mathrm{R}$-module and $\mathrm{Ann}_{\mathrm{R}}(\mathrm{S})$ is a graded $\mathrm{I}$-prime ideal of $\mathrm{R}$, then $\mathrm{S}$ is a graded $\mathrm{I}-$ second submodule of $\mathrm{M}$.

Proof. (i) Let $a_{g} b_{h} \in A n n_{R}(S) \backslash \operatorname{IAnn}_{R}(S)$ for some $a_{g}, b_{h} \in h(R)$. Then $a_{g} S \subseteq\left(0: M b_{h}\right)$. As $a_{g} b_{h} \notin \operatorname{IAnn}_{R}(S)$ and $\operatorname{Ann}_{R}\left(\left(S:_{M} I\right)\right) \subseteq \operatorname{IAnn}_{R}(S)$, we have $a_{g} b_{h} \notin A n n_{R}((S: M I))$. This implies that $a_{g} \notin\left(\left(0:_{M} b_{h}\right):_{R}(S: M I)\right)$. Thus $a_{g} \in \operatorname{Ann}_{R}(S)$ or $S \subseteq\left(0: b_{h}\right)$. Hence $a_{g} \in \operatorname{Ann}_{R}(S)$ or $b_{h} \in \operatorname{Ann}_{R}(S)$, as needed.

(ii) Let $r_{g} \in\left(K:_{R} S\right) \backslash\left(K:_{R}(S: M I)\right)$ for some $r_{g} \in h(R)$ and graded submodule $K$ of $M$. As $M$ is a graded comultiplication R-module, there exists a graded ideal $J$ of $R$ such that $K=(0: M J)$. Thus $r_{g} J \subseteq A n n_{R}(S)$. Since $r_{g} \notin(K: R$ $(S: M I))$, we have $\operatorname{Jr}_{g}\left(S:_{M} I\right) \neq 0$. This implies that $\operatorname{Jr}_{g} \nsubseteq A n_{R}((S: M I))$. Since always $\operatorname{IAnn}_{R}(S) \subseteq \operatorname{Ann}_{R}((S: M I))$, we have $r_{g} J \nsubseteq \operatorname{IAnn}_{R}(S)$. Thus by assumption, $r_{g} \in A \operatorname{Ann}_{R}(S)$ or $J \subseteq A n_{R}(S)$ and so $S \subseteq(0: M J)=K$.

Proposition 4 Let $\mathrm{M}$ be a graded $\mathrm{R}$-module and $\mathrm{I}$ a graded ideal of $\mathrm{R}$. Let $\mathrm{N}$ be a graded I-second submodule of $\mathrm{M}$. Then we have the following statements.

(i) If $\mathrm{K}$ is a graded submodule of $\mathrm{M}$ with $\mathrm{K} \subset \mathrm{N}$, then $\mathrm{N} / \mathrm{K}$ is a graded $\mathrm{I}$-second submodule of $\mathrm{M} / \mathrm{K}$.

(ii) Let $\mathrm{N}$ be a graded finitely generated submodule of $\mathrm{M}, \mathrm{S} \subseteq \mathrm{h}(\mathrm{R})$ be a multiplicatively closed subset of $\mathrm{R}$ with $\operatorname{Ann}_{\mathrm{R}}(\mathrm{N}) \cap \mathrm{S}=\emptyset$. Then $\mathrm{S}^{-1} \mathrm{~N}$ is a graded $\mathrm{S}^{-1} \mathrm{I}-$ second submodule of $\mathrm{S}^{-1} \mathrm{M}$. 
Proof. (i) This follows from the fact that $r_{g} \notin\left(r_{g}(S / K):_{R}\left(S / K:_{M / K} I\right)\right)$ implies that $r_{g} \notin\left(r_{g} S: R(S: M I)\right)$.

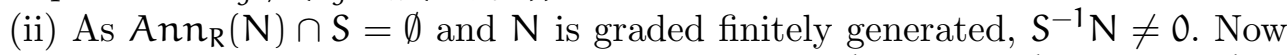
the claim follows from the fact that $r / s \notin\left((r / s) S^{-1} N: S^{-1}\left(S^{-1} N: S^{-1} M S^{-1} I\right)\right)$ implies that $\mathrm{r} \notin\left(\mathrm{rN}:_{\mathrm{R}}\left(\mathrm{N}:_{\mathrm{M}} \mathrm{I}\right)\right)$.

Proposition 5 Let $\mathrm{I}$ be a graded ideal of $\mathrm{R}, \mathrm{M}$ and $\mathrm{M}^{\prime}$ be graded $\mathrm{R}$-modules, and let $\mathrm{f}: \mathrm{M} \rightarrow \mathrm{M}^{\prime}$ be an R-monomorphism. If $\mathrm{N}^{\prime}$ is a graded I-second submodule of $\mathrm{M}^{\prime}$ such that $\mathrm{N}^{\prime} \subseteq \operatorname{Im}(\mathrm{f})$, then $\mathrm{f}^{-1}\left(\mathrm{~N}^{\prime}\right)$ is a graded I-second submodule of $\mathrm{M}$.

Proof. As $N^{\prime} \neq 0$ and $N^{\prime} \subseteq \operatorname{Im}(f)$, we have $f^{-1}\left(N^{\prime}\right) \neq 0$. Let $r_{g} \notin\left(r_{g} f^{-1}\left(N^{\prime}\right): R\right.$ $\left.\left(f^{-1}\left(N^{\prime}\right): M I\right)\right)$; then one can see that $r_{g} \notin\left(r_{g} N^{\prime}: R\left(N^{\prime}: M I\right)\right)$ using assumptions. Thus $r_{g} N^{\prime}=0$ or $r_{g} N^{\prime}=N^{\prime}$. This implies that $r_{g} f^{-1}\left(N^{\prime}\right)=0$ or $r_{g} f^{-1}\left(N^{\prime}\right)=f^{-1}\left(N^{\prime}\right)$, as requested.

Theorem 13 Let $\mathrm{I}$ be a graded ideal of $\mathrm{R}, \mathrm{M}_{1}, \mathrm{M}_{2}$ be graded $\mathrm{R}$-modules, and let $\mathrm{N}$ be a graded submodule of $\mathrm{M}_{1}$. Then $\mathrm{N} \oplus 0$ is a graded $\mathrm{I}$-second submodule of $\mathrm{M}_{1} \oplus \mathrm{M}_{2}$ if and only if $\mathrm{N}$ is a graded I-second submodule of $\mathrm{M}_{1}$ and for $r_{g} \in\left(r_{g} N: R\left(N: M_{1} I\right)\right), r_{g} N \neq 0$, and $r_{g} N \neq N$, we have $r_{g} \in \operatorname{Ann}_{R}\left(\left(0::_{M_{2}}\right.\right.$ I)).

Proof. $(\Rightarrow)$ Let $r_{g} \notin\left(r_{g} N:_{R}\left(N:_{M_{1}} I\right)\right)$. Then $r_{g} \in\left(r_{g}(N \oplus 0):_{R}(N \oplus 0: M I)\right)$. Since $N \oplus 0$ is a graded I-second submodule, either $r_{g}(N \oplus 0)=N \oplus 0$ or $r_{g}(N \oplus 0)=0 \oplus 0$. Thus either $r_{g} N=N$ or $r_{g} N=0$, so $N$ is graded I-second. Now, let $r_{g} \in\left(r_{g} N: R\left(N: M_{1} I\right)\right), r_{g} N \neq 0$, and $r_{g} N \neq N$. Assume on the contrary that $r_{g} \in \operatorname{Ann}_{R}\left(\left(0: M_{2} I\right)\right)$. Then there exists $y_{h} \in M_{2}$ such that $I y_{h}=0$ and $r_{g} y_{h} \neq 0$. This implies that $r_{g}\left(0, y_{h}\right) \in r_{g}(N \oplus 0: M I) \backslash r_{g}(N \oplus 0)$. So since $N \oplus 0$ is a graded I-second submodule, either $r_{g}(N \oplus 0)=N \oplus 0$ or $r_{g}(N \oplus 0)=0 \oplus 0$. Thus either $r_{g} N=N$ or $r_{g} N=0$, which is a contradiction. Therefore, $r_{g} \in \operatorname{Ann}_{R}\left(\left(0: M_{2} I\right)\right)$.

$(\Leftarrow)$ Let $r_{g} \notin\left(r_{g}(N \oplus 0): R(N \oplus 0: M I)\right)$. Then if $r_{g} N=N$ or $r_{g} N=0$, the result is clear. So suppose that $r_{g} N \neq N$ and $r_{g} N \neq 0$. We show that $r_{g}\left(r_{g} N: R\left(N: M_{1} I\right)\right)$ and this contradiction proves the result because $N$ is a graded I-second submodule of $M_{1}$. Assume on the contrary that $r_{g} \in\left(r_{g} N: R\right.$ $\left.\left(N:_{M_{1}} I\right)\right)$. Then by assumption, $r_{g} \in \operatorname{Ann}_{R}\left(\left(0: M_{2} I\right)\right)$. This implies that if $\left(x_{h}, y_{h}\right) \in N \oplus\left(0::_{M} I\right)$, then $r_{g}\left(x_{h}, y_{h}\right) \in r_{g}(N \oplus 0)$. Therefore, $r_{g} \in$ $\left(r_{g}(N \oplus 0):_{R}(N \oplus 0: M I)\right)$, which is a desired contradiction. 
A non-zero graded R-module $M$ is said to be graded secondary if for each $a_{g} \in h(R)$ the endomorphism of $M$ given by multiplication by $a_{g}$ is either surjective or nilpotent [4].

Corollary 3 Let $\mathrm{I}$ and $\mathrm{P}$ be graded ideals of $\mathrm{R}, \mathrm{M}_{1}, \mathrm{M}_{2}$ be graded $\mathrm{R}$-modules, and let $\mathrm{N}$ be a graded submodule of $\mathrm{M}_{1}$. Let $\mathrm{S}_{\mathrm{i}}(1 \leq i \leq \mathrm{n})$ be graded $\mathrm{P}$ secondary submodules of $\mathrm{M}_{1}$ with $\sum_{i=1}^{n} S_{i}=\left(\mathrm{N}: \mathrm{M}_{1}\right.$ I). If $\mathrm{N}$ is a graded I-second submodule of $\mathrm{M}_{1}$ and $\mathrm{P} \subseteq \operatorname{Ann}_{\mathrm{R}}\left(\left(0:_{\mathrm{M}_{2}} \mathrm{I}\right)\right)$, then $\mathrm{N} \oplus 0$ is a graded I-second submodule of $\mathrm{M}_{1} \oplus \mathrm{M}_{2}$.

Proof. Let $r_{g} \in\left(r_{g} N:_{R}\left(N:_{M_{1}} I\right)\right), r_{g} N \neq 0$, and $r_{g} N \neq N$. Then we will prove that $r_{g} \in \operatorname{Ann}_{R}\left(\left(0: M_{2} I\right)\right)$ and hence the result is obtained by Theorem 13. Assume on the contrary that $r_{g} \notin A n n_{R}\left(\left(0: M_{M_{2}} I\right)\right)$. Hence $r \notin P$. On the other hand, $r_{g}\left(\sum_{i=1}^{n} S_{i}\right)=r_{g}\left(N:_{M_{1}} I\right) \subseteq r_{g} N$. But $\sum_{i=1}^{n} S_{i}$ is a graded P-secondary submodule by [4], so either $r_{g}\left(\sum_{i=1}^{n} S_{i}\right)=\sum_{i=1}^{n} S_{i}$ or $r_{g} \in P$. This implies that $r_{g} N=N$ or $r_{g} \in P$, which is a contradiction. Thus $r_{g} \in A n_{R}\left(\left(0: M_{2} I\right)\right)$.

Theorem 14 Let $\mathrm{I}$ be a graded ideal of $\mathrm{R}$ and $\mathrm{M}$ be a graded $\mathrm{R}$-module. Then we have the following.

(i) If $\bigcap_{\mathfrak{n}=1}^{\infty} I^{\mathrm{n}} \mathrm{M}=0$ and every proper graded submodule of $\mathrm{M}$ is graded I-prime, then every non-zero graded submodule of $\mathrm{M}$ is graded $\mathrm{I}-$ second.

(ii) If $\sum_{n=1}^{\infty}\left(0: M I^{n}\right)=M$ and every non-zero graded submodule of $\mathrm{M}$ is graded I-second, then every proper graded submodule of $\mathrm{M}$ is graded Iprime.

Proof. (i) Let $S$ be a non-zero graded submodule of $M, r_{g} \in(K: R S) \backslash(K: R$ $\left(S:_{M} I\right)$ ) for some $r_{g} \in h(R)$ and a graded submodule $K$ of $M$ and $r_{g} S \neq 0$. If $r_{g} S \nsubseteq I K$, then as $K$ is graded I-prime, we have $r_{g} M \subseteq K$ or $S \subseteq K$. If $r_{g} M \subseteq K$, then $r_{g}(S: M I) \subseteq K$ which is a contradiction. So $S \subseteq K$ and we are done. Now suppose that $r_{g} S \subseteq I K$. As $r_{g} S \neq 0$ and $\bigcap_{n=1}^{\infty} I^{n} K=0$, there exists a positive integer $t$ such that $r_{g} S \nsubseteq I^{t} \mathrm{~K}$. Therefore, there is a positive integer $\mathrm{h}$ such that $\mathrm{r}_{\mathrm{g}} S \subseteq \mathrm{I}^{\mathrm{h}-1} \mathrm{~K}$ but $\mathrm{r}_{\mathrm{g}} \mathrm{S} \nsubseteq \mathrm{I}^{\mathrm{h}} \mathrm{K}$, where $2 \leq \mathrm{h} \leq \mathrm{t}$. Thus since $\mathrm{I}^{\mathrm{h}-1} \mathrm{~K}$ is graded I-prime, $\mathrm{S} \subseteq \mathrm{I}^{\mathrm{h}-1} \mathrm{~K}$ or $\mathrm{r}_{\mathrm{g}} \mathrm{M} \subseteq \mathrm{I}^{\mathrm{h}-1} \mathrm{~K}$. If $\mathrm{r}_{\mathrm{g}} \mathrm{M} \subseteq \mathrm{I}^{\mathrm{h}-1} \mathrm{~K}$, then $r_{g}(S: M I) \subseteq K$ which is a contradiction. So $S \subseteq I^{h-1} K$ as needed.

(ii) Let $P$ be a proper graded submodule of $M, r_{g} K \subseteq P \backslash I P$ for some $r_{g} \in h(R)$ and a graded submodule $K$ of $M$ and $r_{g} M \nsubseteq P$. If $r_{g}(K: M I) \nsubseteq P$, then as $K$ is graded I-second, we have $r_{g} K=0$ or $K \subseteq P$. If $r_{g} K=0$, then $r_{g} K \subseteq$ IP which is a contradiction. So $K \subseteq P$ and we are done. Now suppose that $r_{g}(K: M I) \subseteq P$. 
As $r_{g} M \nsubseteq P$ and $\sum_{n=1}^{\infty}\left(K: M I^{n}\right)=M$, there exists a positive integer $t$ such that $r_{g}\left(K: M I^{t}\right) \nsubseteq \subseteq P$. Therefore, there is a positive integer $h$ such that $r_{g}(K: M$ $\left.\mathrm{I}^{\mathrm{h}-1}\right) \subseteq \mathrm{P}$ but $r_{\mathrm{g}}\left(\mathrm{K}: \mathrm{M}_{\mathrm{M}} \mathrm{I}^{\mathrm{h}}\right) \nsubseteq \mathrm{P}$, where $2 \leq \mathrm{h} \leq \mathrm{t}$. Thus since $\left(\mathrm{K}:_{\mathrm{M}} \mathrm{I}^{\mathrm{h}-1}\right)$ is graded I-second, $\left(K:_{M} I^{h-1}\right) \subseteq P$ or $r_{g}\left(K:_{M} I^{h-1}\right)=0$. If $r_{g}\left(K:_{M} I^{h-1}\right)=0$, then $0=r_{g} K \subseteq I P$ which is a contradiction. So $K \subseteq\left(K: I I^{h-1}\right) \subseteq P$, as needed.

\section{References}

[1] R. Abu-Dawwas, M. Bataineh, Graded prime submodules over noncommutative rings, Vietnam J. Math., 46(3) (2018), 681-692.

[2] H. Ansari-Toroghy, F. Farshadifar, Graded comultiplication modules, Chiang Mai J. Sci., 38(3) (2011), 311-320.

[3] S. Ebrahimi Atani, On graded prime submodules, Chiang Mai J. Sci., 33(1) (2006), 3-7.

[4] S. Ebrahimi Atani, F. Farzalipour, On graded secondary modules, Turk. J. Math., 31 (2007), 371-378.

[5] F. Farshadifar, H. Ansari-Toroghy, I-second submodules of a module, Matematički Vesnik, 72(1) (2020), 58-65.

[6] F. Farshadifar, H. Ansari-Toroghy, $\psi$-second submodules of a module, Beitr Algebra Geom, 61 (2020), 571-578.

[7] F. Farzalipour, P. Ghiasvand, On the union of graded prime submodules, Thai. J. of Math., 9(1) (2011), 49-55.

[8] P. Ghiasvand, F. Farzalipour, Some properties of graded multiplication modules, Far East J. Math. Sci., 34 (2009), 341-352.

[9] P. Ghiasvand, F. Farzalipour, On graded weak multiplication modules, Tamkang J. of Math., 43(2) (2012), 171-177.

[10] P. Ghiasvand, F. Farzalipour, On the graded primary radical of graded submodules, Advances and Applications in Math. Sci., 10(1) (2011), 1-7.

[11] N. Nastasescu, F. Van Oystaeyen, Graded Rings Theory, Mathematical Library 28, North Holand, Amsterdam, 1937. 
[12] N. Nastasescu, F. Van Oystaeyen, Methods of Graded Rings, Lecture Notes in Mathematics, vol. 1836. Springer, Berlin, 2004.

[13] J. P. Serre, Local Algebra, Springer Verlag, 2000.

[14] M. Refaei, K. Alzobi, On graded primary ideals, Turk. J. Math., 28(3) (2004), 217-229.

Received: July 29, 2020 